\title{
LUDOMUSICOLOGÍA: NORMALIZANDO EL ESTUDIO DE LA MÚSICA DE LOS VIDEOJUEGOS
}

\section{LUDOMUSICOLOGY: NORMALISING THE STUDY OF VIDEO GAME MUSIC}

\author{
Juan Pablo Fernández-Cortés \\ Universidad Autónoma de Madrid \\ juanpablo.fernandez@uam.es \\ ORCID ID: 0000-0002-0103-3440
}

\begin{abstract}
Resumen
El estudio de la música de videojuegos ha alcanzado en las dos últimas décadas su madurez y aceptación en medios académicos. Esta subdisciplina, conocida comúnmente como Ludomusicología, se plantea aún preguntas básicas sobre cómo se puede investigar. Este artículo pretende dar a conocer la situación actual y reflexionar sobre algunas de las principales líneas de trabajo de los estudios sobre la música de los videojuegos y sus culturas, un campo de investigación en desarrollo permanente que, hasta la fecha, ha recibido escasa consideración en el ámbito académico hispánico.
\end{abstract}

\section{Palabras clave}

Videojuegos, ludomusicología, interacción, alfabetización ludomusical, inmersión, performatividad, diégesis sonora.

Las tecnologías digitales han transformado la realidad en la que vivimos, han modificado las formas de expresión artística y han contribuido a sentar las bases para la creación de nuevas relaciones culturales. La necesidad de comprender los profundos cambios derivados de la tecnología que han aflorado en las últimas décadas ha contribuido a promover el desarrollo académico de nuevos paradigmas y la renovación de enfoques con el fin de integrar en las agendas de investigación el estudio de los productos y dispositivos gestados en la cultura digital. La reflexión crítica sobre la urgencia de ampliar el campo de trabajo a las exigencias planteadas por la revolución digital enmarca las primeras manifestaciones del interés por el estudio sistemático de la música de los videojuegos, una subdisciplina

\begin{abstract}
In the past two decades, the study of video game music has come into its own and gained acceptance in the academic community. This subdiscipline, now commonly referred as Ludomusicology, is still attempting basic questions concerning how it can be researched. This article aims to present the current situation and to reflect about some of the main lines of research related to the music of video games and their culture, a field of ongoing research that has received little attention in Hispanic academia up to the present time.
\end{abstract}

\section{Keywords}

Video games, ludomusicology, interactivity, game musical literacy, immersion, performativity, sound diegesis.

que desde hace unos años se conoce con el neologismo Ludomusicología. ${ }^{1}$

${ }^{1}$ Ludomusicología es una traducción del neologismo inglés Ludomusicology que fue acuñado de la unión de los conceptos Ludology (estudio de los juegos y de sus mecánicas como fenómeno cultural) y Musicology. El término se usa por primera vez en 2007 en un proyecto de Guillaume Laroche, estudiante de la University of Alberta (Canadá) y es de nuevo redefinido y empleado de forma sistemática por Roger Moseley en 2013. Véase Tasneem Karbani, Summer research project was music to student's ears, <https://sites.ualberta. ca/ publicas/folio/45/01/04.html> [consulta: 15/03/2020]; y Roger Moseley, "Playing Games with Music (and Vice Versa): Ludomusicological Perspectives on Guitar Hero and Rock 
Este artículo tiene como objetivo dar a conocer la situación actual y algunas de las principales líneas de trabajo de los estudios sobre la música de los videojuegos, un campo de investigación en desarrollo permanente que, hasta la fecha, ha recibido escasa consideración en el ámbito académico hispánico. El trabajo se divide en tres partes. En la primera se contextualizan los orígenes de la Ludomusicología en el marco del interés por la consideración del videojuego como objeto de estudio que surgió a principios del presente siglo y los problemas a los que, desde sus orígenes, ha tenido que enfrentarse para ser reconocida y valorada dentro del mundo académico y profesional. El segundo apartado es una síntesis crítica con aportaciones personales sobre algunos enfoques que han comenzado a consolidarse como ámbitos de trabajo de la Ludomusicología y cuyos planteamientos y resultados señalan la necesidad de modelar nuevos paradigmas de investigación para analizar la música de los productos digitales de carácter lúdico. En un primer punto se estudian, a través de varios ejemplos concretos, las singularidades de la creación de significado en la música de videojuegos a partir del concepto de alfabetización ludomusical. A continuación, se analiza la importancia de emplear nuevas metodologías, fuentes y herramientas conceptuales - como la inmersión, la performatividad y las singulares formas de diégesis - a la hora de valorar adecuadamente los productos musicales videolúdicos. Para concluir, se reflexiona brevemente sobre los valores que puede aportar el estudio de la música de los videojuegos, al desmantelar las barreras entre lo real y lo virtual, para renovar y enriquecer el discurso académico de la Musicología.

\section{MÚSICA Y VIDEOJUEGOS: EN BUSCA DE UN RECONOCIMIENTO ACADÉMICO}

La creación y desarrollo de un área de investigación que permitiera interrogar al videojuego en su especificidad fue el objetivo fundamental de los primeros teóricos que se dedicaron al estudio de los productos videolúdicos. El interés académico por los juegos digitales comenzó en las últimas décadas del siglo XX, primero dentro del ámbito de la Antropología y de los Estudios Culturales y, más tarde, como parte de los trabajos sobre la multimedialidad

Band", en Taking It to the Bridge: Music as Performance, ed. Nicholas Cook y Richard Pettengill (Ann Arbor: University of Michigan Press, 2013), pp. 279-318. y lo hipertextual. Es a principios del siglo XXI cuando empieza a visibilizarse una nueva disciplina autónoma, la Ludología o game studies que, con un enfoque más amplio, se asentará progresivamente gracias a la aparición de publicaciones, grupos de investigación y eventos académicos centrados en analizar los problemas específicos del estudio de los videojuegos y otros productos lúdicos. ${ }^{2}$ En este contexto de búsqueda de una independencia académica se enmarcan también los primeros trabajos de investigación sobre la música de los videojuegos que, desde sus inicios, reivindicaron la necesidad de desarrollar herramientas específicas para estudiar una nueva forma de expresión sonora cuyos resultados no pueden explicarse únicamente a través del análisis de una notación musical escrita o de su reproducción fonográfica.

Intentar abrirse camino en un campo de investigación nuevo como el estudio de la música de los videojuegos supuso enfrentarse al desafío que conllevaba el reconocimiento y la consideración de la comunidad académica. Cuando en 1999 Matthew Belinkie escribió su seminal panorámica histórica sobre la música de los productos videolúdicos vio necesario comenzar por reivindicar - desde el mismo título del artículo que aludía a su valor como objeto de estudio ("Video Game Music: Not Just Kids Stuff") - la seriedad de un objeto de investigación que hasta entonces había sido considerado como un simple complemento de un producto de entretenimiento juvenil sin mayores pretensiones. ${ }^{3}$ Karen Collins, una de las pioneras de la Ludomusicología, recordaba que, en los inaugurales artículos académicos que se dedicaron al estudio de la música de los videojuegos, publicados en los primeros años del siglo XXI, parecía necesario incluir siempre un preámbulo para justificar con datos y cifras la relevancia de la industria del videojuego en términos de valor económico, demografía e impacto cultural. ${ }^{4} \mathrm{~A}$ este hecho se sumaban

\footnotetext{
2 Sobre este tema, véase Antonio José Planells de la Maza, "La emergencia de los Game Studies como disciplina propia: investigando el videojuego desde las metodologías de la comunicación”, Historia y Comunicación Social, 18 (2004), pp. 519-528.

3 Matthew Belinkie, "Video Game Music: Not Just Kid Stuff", Videogame Music Archive <https:/web.archive.org/ web/20020613143431/http://www.vgmusic.com/vgpaper.sht$\mathrm{ml}>$. Archivado del original publicado el 15/12/2009 [consulta: $15 / 03 / 2020]$.

${ }^{4}$ Karen Collins, Game Sound: An Introduction to the History, Theory, and Practice of Video Game Music and Sound Design (Cambridge, MA: MIT Press Book), p. ix.
} 
las dificultades a las que debía enfrentarse cualquier investigador que quisiera trabajar sobre productos digitales en un contexto radicalmente diferente al que nos desenvolvemos en la actualidad. En un reciente artículo, Collins reflexionaba sobre los obstáculos que ella misma tuvo que superar cuando comenzó, en los primeros años del siglo XXI, sus investigaciones para Game Sound, obra que se considera la primera monografía académica dedicada a la teoría, historia y práctica de la música y el diseño de sonido en los videojuegos:

Echando la vista atrás, cuando comencé a investigar para Game Sound en 2002, el contexto para escribir un libro era muy diferente. La Web todavía estaba en pañales y resultaba difícil conseguir información para la investigación. En aquellos días no existía una comunidad de fans, no había archivos con recopilaciones de materiales y había muy poca información. Tampoco pude localizar otros trabajos académicos sobre el sonido en los videojuegos. La mayoría de las revistas aún no estaban indexadas en línea, y ¡teníamos que ir físicamente a una biblioteca! Había muy pocas entrevistas con diseñadores de sonido o compositores en internet (y, por supuesto, ninguna en vídeo), y no existían las redes sociales para contactar con gente. [...] Afortunadamente, en ese momento, a la gente le encantaba regalarme sus viejas computadoras, que por entonces no valían nada, pero que ahora se han revalorizado, y recuerdo con mucho cariño rescatar una colección de treinta y dos Commodores del vertedero. Ahora me sorprende la gran metáfora que supone intentar rescatarlo todo de la basura. ${ }^{5}$

5 Karen Collins, "Game Sound: Reverberations", Journal of Sound and Music in Games, 1/1 (2020), pp. 100-101: "Looking back, when I first started research for Game Sound in 2002, it was a very different world in which to write the book. The web was still much in its infancy and getting information for the research was difficult. There wasn't the fan community online in those days, no collected archives of material, and very little information. There was also no other scholarly writing about game sound available that I could find at the time. Most journals were not yet indexed online, and we had to physically go to a library! There were very few interviews with sound designers or composers online (and certainly no video), and there was no social media to speak of in which to get in touch with people. [...] Fortunately, at that time, people were only too happy to give me their old computers, which were worthless then but have gained value now, and I recall fondly rescuing a collection of thirty-two Commodores from landfill. It strikes me now what a great metaphor that is, trying to rescue it all from the dump". Todas las traducciones presentadas en este trabajo están realizadas por el autor del artículo.
Tanto el mundo profesional como el académico parecían por entonces muy poco receptivos al estudio de la música de los videojuegos. Así relata Collins las dificultades que tuvo que afrontar en los primeros años de su actividad laboral:

Las entrevistas de trabajo que conseguí en aquellos días se desvanecieron rápidamente cuando comenté que trabajaba sobre la música de los videojuegos. En ese momento, la respuesta de otros académicos a cualquier cosa relacionada con los juegos era de escepticismo y rechazo. Los que se aventuraron a echar un vistazo [a mi trabajo] lo vieron como un lodazal, fruncieron el ceño y se encogieron de hombros. ${ }^{6}$

Dos décadas después, los investigadores que trabajan sobre la música de videojuegos ya no necesitan dedicar una cantidad considerable de su tiempo a reivindicar el valor de su campo de trabajo. Tanto en Estados Unidos como en una buena parte de Europa, la Ludomusicología ha entrado en un proceso de normalización académica, resultado de una sustancial labor previa de difusión y edición de monografías, libros en colaboración y capítulos en revistas que han contribuido a sentar las bases teóricas y a definir algunas líneas de investigación que comienzan a consolidarse. ${ }^{7}$ Asimismo, la celebración de congresos y otros eventos científicos ha favorecido la creación de redes de contacto entre investigadores de distintos países. En 2012, el Ludomusicology Research Group formado originalmente por los investigadores radicados en el Reino Unido Michiel Kamp, Tim Summers y Mark Sweeney organizaron en la Universidad de Oxford la primera reunión científica dedicada específicamente a la música de videojuegos. Este evento fue el germen de un congreso que se ha celebrado en distintos lugares de Europa bajo el título genérico de Ludo. Dos años más tarde, en Youngstown State University (Estados Unidos) tuvo lugar la North American Conference on Video Game Music (NA-

${ }^{6}$ Collins, "Game Sound: Reverberations", p. 101: "What job interviews I managed to obtain in those days quickly dissipated when I said I was working on game music. The response of many other scholars at the time to anything related to games was mostly skepticism and disdain. Those who ventured to take a look saw my field of mud, frowned, and shrugged".

${ }^{7}$ La Society for the Study of Sound and Music in Games está realizando desde hace unos años un intento por recopilar toda la bibliografía sobre este tema publicada hasta la fecha; véase $<$ https://www.sssmg.org/wp/bibliography/> [consulta: 15/03/2020]. 
$C V G M)$. Ambas iniciativas se han repetido desde entonces con periodicidad anual. Gracias al impulso de estos encuentros científicos se funda, a finales del 2016, la primera sociedad internacional dedicada al estudio de la música y el sonido de los videojuegos, la Society for the Study of Sound and Music in Games (SSSMG). Los promotores de esta organización fueron los miembros del Ludomusicology Research Group junto con los organizadores de la NACVGM y del congreso Audio Mostly, un evento internacional que, desde su primera edición en 2006, también ha centrado una parte de sus intereses en el estudio del sonido de los videojuegos. La madurez de esta sociedad, de la que forman parte en la actualidad más de doscientos miembros de todo el mundo, ha quedado constatada con la publicación en enero de 2020 del primer número de Journal of Sound and Music in Games (University of California Press). Esta nueva revista académica - que funciona como órgano de difusión científica de la SSSMG - publica trabajos tanto de profesionales de la industria como de investigadores con perspectivas diversas que incluyen planteamientos metodológicos que pueden enmarcarse en la Ludomusicología, estudios técnicos sobre sonología y textos con enfoques antropológicos y sociológicos, entre otros.

A pesar de la productiva actividad que la Ludomusicología ha manifestado en las últimas décadas a nivel internacional, la comunidad académica hispánica ha mostrado, hasta la fecha, una cierta resistencia para aceptar la música de videojuegos como un campo de investigación equiparable al trabajo que se viene realizando en relación con el estudio de la música en otros medios audiovisuales admitidos y legitimados como pueden ser el cine, la publicidad o la televisión. Cabe señalar, no obstante, la labor individual de algunos investigadores que, con enfoques diversos y desde campos como la comunicación audiovisual, la sociología de la música o la musicología, han abordado de forma puntual esta temática. ${ }^{8}$ Asimismo,

8 Véanse, como muestra, por orden cronológico: Mónica Moreira Cury, "La música de los videojuegos: modalidades de uso y su relación con el imaginario social. Un estudio sobre la banda sonora del juego 'Final Fantasy VI'", tesis de máster en Musicología, Universidad de Chile, 2004; Alfredo Aracil, "Música y efectos sonoros en los videojuegos. Apuntes sobre la pérdida de su identidad", en La música en los medios audiovisuales, ed. Matilde Olarte (Salamanca: Universidad de Salamanca, 2005), pp. 267-282; Julio Montero, "Pautas compositivas en los videojuegos del siglo XXI", en La música en el lenguaje audio- en la última década, la música de los videojuegos ha comenzado a tener presencia en congresos y eventos académicos sobre música y cultura audiovisual celebrados tanto en España como en Latinoamérica. Conocer las causas de esta situación no es una tarea sencilla. A los problemas de tipo organizativo y presupuestario, siempre presentes en las políticas que rigen los centros de investigación y formación, se unen las dificultades de los investigadores y profesores universitarios para consolidar nuevas áreas de investigación y plantear enfoques que posibiliten la renovación de unos paradigmas y modelos epistemológicos que, en muchas ocasiones, no concuerdan con las necesidades e intereses de la sociedad digital. ${ }^{9}$

visual. Aproximaciones multidisciplinares a una comunicación mediática (Salamanca: Plaza Universitaria Ediciones, 2009), pp. 585-598; Antonio Jesús González Portillo, “La música en el videojuego como banda sonora: definición, antecedentes históricos y desarrollo hasta la actualidad", tesis doctoral, Universidad de Málaga, 2010; Israel V. Márquez, "La influencia de los videojuegos en la música popular", en La música en el lenguaje audiovisual. Aproximaciones multidisciplinares a una comunicación mediática, ed. Teresa Fraile y Eduardo Viñuela (Sevilla: Arcibel, 2012), pp. 511-521; Mario Sánchez, "Las funciones de la música en el videojuego: la función ludoinmersiva", en Pantallas pequeñas, ¿músicas menores?, ed. José A. Bornay Llinares, Vicente J. Ruíz Antón y Jenaro Vera Guarinos (Alicante: Letra de Palo, 2015), pp. 287-302; Juan Pablo Fernández-Cortés, "Por las sendas de la Ludomusicología: tecnología y estética en la música de videojuegos durante el siglo XX", Anales de la Real Academia Canaria de Bellas Artes de San Miguel Arcángel. RACBA, 10 (2017), pp. 195-210; y Gonzalo Parrilla, "Conceptualización de la terminología ludomusicológica", Itamar, 5 (2019), pp. 57-68.

9 El estudio de la música de los videojuegos ha comenzado a visibilizarse tímidamente en las últimas ediciones de eventos científicos celebrados en España tales como el simposio internacional La creación musical en la banda sonora: Perspectiva sonora (TecnoCampus) o el Congreso MUCA (Universidad de Murcia). Entre las iniciativas de investigación y divulgación académica en español cabe citar también la actividad de Ludum, grupo gestado en la Universidad de Chile que organizó en 2018 el I Encuentro Nacional de Ludomusicología. Sobre la actividad de este grupo, véase Ariel Grez, Video Game Music Research in Chile, <https://www.ludomusicology.org/2019/08/30/video-game-music-research-in-chile/.> [consulta: 15/03/2020]. En España, Juan Pablo Fernández-Cortés mantiene desde 2018 el blog académico Ludomusicología. Investigaciones y reflexiones sobre la música de los videojuegos y sus culturas, <https://ludomusico.hypotheses.org/> [consulta: 15/03/2020]. 


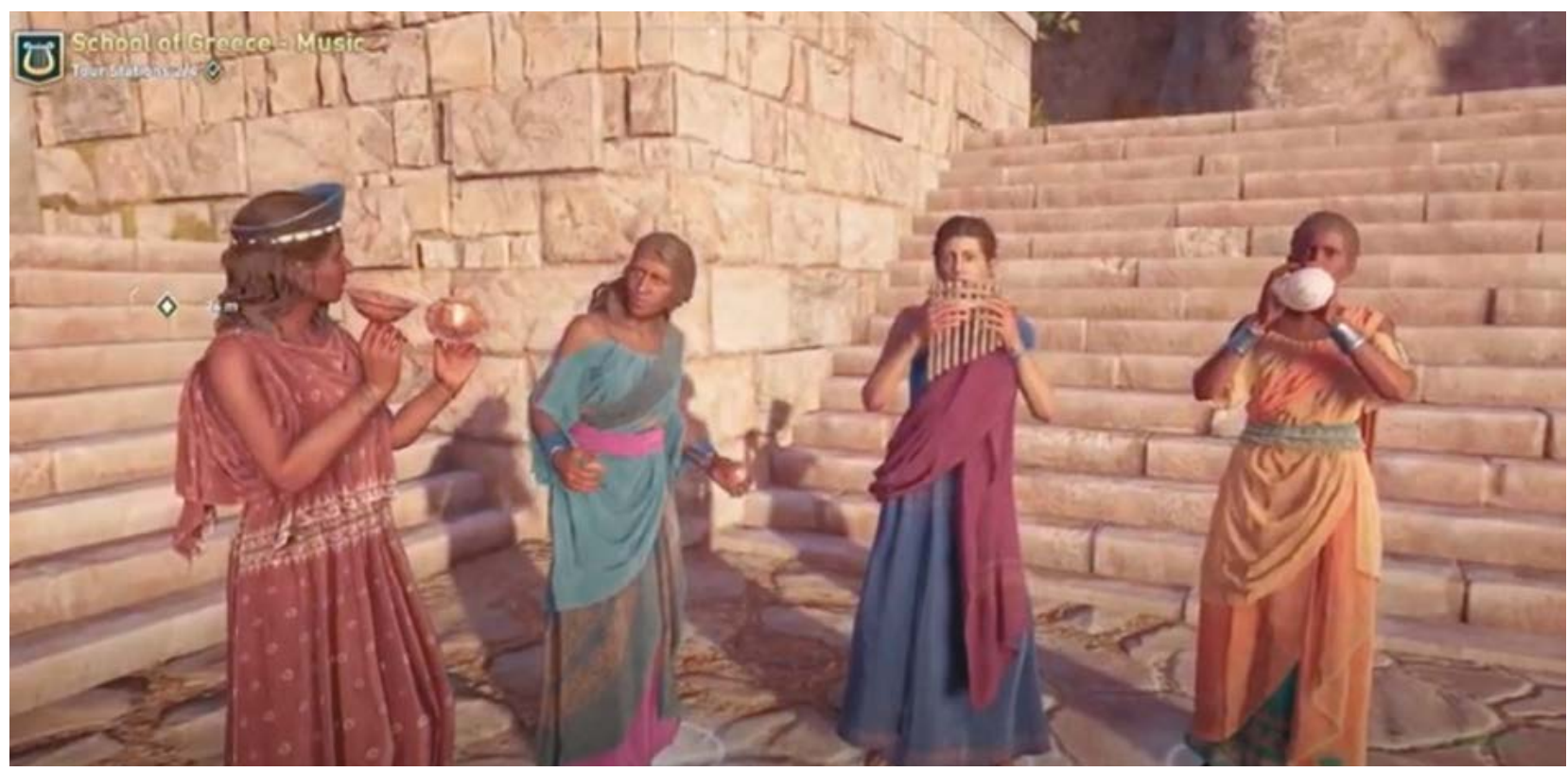

Figura 1. Interpretación musical en el exterior del Odeón de Pericles. Assassin's Creed Odyssey. Discovery Tour (Ubisoft, 2019).

\section{ALFABETIZACIÓN LUDOMUSICAL. CONSTRUYENDO SIGNIFICADO EN LA MÚSICA DE VIDEOJUEGOS}

Cuando se observa un jugador del siglo XXI, con sus manos ocupadas por el mando de una videoconsola, pasear plácidamente por una fiel reproducción del Odeón de Pericles y detenerse frente a un grupo de mujeres para escuchar una pieza musical interpretada con instrumentos que evocan las formas y sonoridades de la Grecia clásica - como sucede en uno de los episodios del Discovery Tour de Assassin's Creed Odyssey (Ubisoft, 2019) - se advierte de inmediato que, al margen de los aspectos meramente lúdicos, la música de los videojuegos pertenece a un complejo ecosistema digital que genera una multiplicidad de mensajes codificados (véase Figura 1). ${ }^{10}$

Producir significado a partir de los elementos y referencias que configuran un videojuego no es una tarea simple e implica desarrollar una serie de competencias de

${ }^{10}$ Los instrumentos que aparecen en la escena reproducen con variable fidelidad organológica krótalos, címbalos, un syrinx con nueve tubos y una caracola que podría identificarse con un kóchlos. tipo intelectual, social y ético que permiten interactuar con la información y recrearla de un modo crítico. El complejo proceso a través del cual se genera el significado en un videojuego forma parte de la alfabetización lúdica (ludoliteracy). Este concepto, que comprende la habilidad de generar y entender los significados en y a través de los videojuegos, ha cristalizado a partir de las propuestas teóricas de José P. Zagal. Además de contemplar un conjunto de habilidades funcionales como saber jugar o ser capaz de crear y desarrollar juegos, la alfabetización lúdica incluye una dimensión más analítica y reflexiva que tiene como objetivo mejorar la competencia para explicar, discutir, describir, enmarcar, situar, interpretar y posicionar los juegos y colocarlos en cuatro contextos distintos: 1) como artefactos culturales; 2) en el contexto de otros juegos, comparando juegos y géneros; 3 ) en el contexto de la plataforma tecnológica que se emplea y 4) deconstruyéndolos y comprendiendo la relación de sus componentes, cómo interaccionan y cómo facilitan ciertas experiencias a los jugadores. ${ }^{11}$

11 José P. Zagal, Ludoliteracy: Defining, Understanding, and Supporting Games Education (Pittsburgh, PA: ETC Press, 2010), pp. 23-24. 
A partir del esquema planteado por Zagal, Isabella van Elferen ha sugerido la conveniencia de considerar una alfabetización ludomusical (game musical literacy) para la música de los videojuegos que combinaría el concepto de alfabetización lúdica con el de alfabetización musical mediática (musical media literacy). Esta última comporta la capacidad para interpretar los códigos de las músicas de cine, televisión o publicidad a partir de una exposición frecuente a ellas. ${ }^{12}$ Van Elferen plantea que, a través de referencias intertextuales procedentes de otros medios audiovisuales, los jugadores de videojuegos pueden desarrollar la capacidad de reconocer rasgos musicales y estilos compositivos que les permiten involucrarse de un modo más activo en las dinámicas de los mundos ludoficcionales. Profundizar en el modelo de la alfabetización lúdica antes citado puede ser, por tanto, una herramienta útil para avanzar en la investigación sobre el proceso de alfabetización ludomusical a través del cual la música de videojuegos construye su significado. Partiendo de esta premisa, en los puntos siguientes se diseña una propuesta personal de aplicación del modelo de Zagal a la música de videojuegos. ${ }^{13}$

\subsection{La música de los videojuegos como parte de un artefacto cultural. Procesos de convergencia}

Disponer los videojuegos en el contexto cultural es el primer paso del esquema propuesto por José P. Zagal. Para comprender los elementos de un videojuego es preciso comenzar por entender las dependencias y correlaciones que se generan entre los productos videolúdicos y otras producciones culturales como los productos impresos (libros, cómics, juegos de mesa) o audiovisuales (películas de cine o series de televisión). La situación se hace especialmente patente cuando se trata de videojuegos que derivan de una misma franquicia, pero puede analizarse también en aquellos que son una adaptación directa de otros medios e incluso en los que comparten las cualidades estéticas o temáticas de un género determinado.

Las relaciones que se llegan a forjar entre los videojuegos y otros productos culturales contribuyen a crear un

12 Isabella van Elferen, "Analysing Game Musical Immersion: The ALI Model", en Ludomusicology: Approaches to Video Game Music, ed. Michiel Kamp, Tim Summers y Mark Sweeney (Sheffield, Reino Unido: Equinox). p. 36.

13 Zagal, Ludoliteracy, pp. 24 -33. complejo proceso de convergencia unificado y coordinado. El jugador-consumidor, al estar familiarizado con un determinado producto, puede identificar y descifrar fácilmente los códigos y elementos que aparecen en un medio distinto. Un ejemplo de ello puede verse rastreando las relaciones que se generan alrededor de la exitosa serie de videojuegos The Witcher (varios desarrolladores, 20072015) que toma como eje argumental la saga de novelas de fantasía del autor Andrzej Sapkowski publicadas a partir de 1990. Antes de trasladarse al mundo videolúdico, las novelas de Sapkowski habían sido adaptadas en formato de cómic en seis volúmenes editados entre 1993 y 1995 que sirvieron también de referencia para elaborar algunos aspectos visuales del primer videojuego. Los libros pasaron a la gran pantalla en la película Wiedźmin (2001) dirigida por Marake Brodszki y en la serie de televisión The Hexer estrenada en 2002 con la banda sonora de Grzegorz Ciechowski, uno de cuyos temas musicales pasó directamente al videojuego The Witcher 3: Wild Hunt (CD Projekt, 2015). ${ }^{14}$ En 2001 se publicó, además, el juego de rol Wiedźmin inspirado también en las novelas Sapkowski y en la década pasada salieron a la venta varios juegos de cartas, series de cómics e incluso un libro con imágenes para colorear destinado a adultos. ${ }^{15} \mathrm{El}$ tema ha vuelto a la actualidad recientemente con la serie The Witcher, estrenada a finales de 2019 en la plataforma Netflix que, aunque retoma como eje argumental las novelas de Sapkowski, emula numerosos elementos visuales de la serie de videojuegos.

La multiplicidad de relaciones y referencias que se generan en los procesos de convergencia es también uno de los aspectos medulares para la alfabetización ludomusical. En muchos videojuegos el significado musical se construye no solo a través de los materiales que se toman directamente de un producto audiovisual o literario precedente, como en el citado caso de la banda sonora de videojuego The Witcher 3: Wild Hunt, sino también a partir de imitaciones, recreaciones o semejanzas que dan lugar a un flujo constante de contenidos que el jugador reconoce e interpreta gracias a un aprendizaje asociativo e implícito. Para ilustrar este proceso, se estudiará a conti-

\footnotetext{
${ }^{14}$ Recep Yilmaz, Nur Erdem y Filiz Resuloğlu, Handbook of Research on Transmedia Storytelling and Narrative Strategies (Hershey, PA: IGI Global, 2018), pp. 111-113.

15 The Witcher Adult Coloring Book (Milwaukie: Dark Horse Comics, 2018).
} 
nuación cómo se elaboró la ambientación musical en los tres juegos de la saga Red Dead, una serie ambientada en México y en el Oeste americano en donde se crea un lenguaje autorreferencial a partir de los tópicos sonoros del cine de género.

El primer videojuego de la saga, Red Dead Revolver (Rockstar, 2004), se sitúa hacia 1880 en el lejano Oeste. Su ambientación sonora se construyó a partir de una antología de temas musicales tomados de películas enmarcadas en el género spaghetti western que tuvo su momento de máximo apogeo entre las décadas de los 60 y 70 del siglo pasado. La selección musical del juego cuenta con temas de importantes compositores como Ennio Morricone, Nino Rota, Bruno Nicolai, Francesco De Masi, Roberto Pregadio o Luis Bacalov, autor del tema musical de la película Lo Chiamavano King (1971) que se emplea para abrir el juego. ${ }^{16}$

Por su relación directa con el medio cinematográfico, la banda sonora de Red Dead Revolver se limita a desplegar un amplio repertorio de los principales tópicos sonoros del spaghetti western que el jugador conoce y puede asociar con diversas situaciones del juego, como los solos de trompeta para los momentos culminantes, los silbidos popularizados a través de las bandas sonoras de Ennio Morricone y otros rasgos tímbricos como las campanas, el uso del látigo o el yunque para las percusiones o el arpa de boca. A pesar de su nula originalidad, este ambiente acústico fue el que se tomó como referencia cuando se encargó a Bill Elm y Woody Jackson la música para Red Dead Redemption (Rockstar, 2009). La acción de este videojuego, que no tiene una relación argumental con el anterior, se traslada al año 1911. El protagonista es John Marston, un proscrito que es coaccionado por dos agentes de la autoridad con el fin de atrapar a uno de sus antiguos compañeros de aventuras. En su propuesta musical, Elm y Jackson mantienen los tópicos sonoros del género, pero introducen ciertas innovaciones en la instrumentación que tienen como finalidad principal caracterizar los tres espacios ficticios de México y Estados Unidos en los que se desarrolla el juego: New Austin, Nuevo Paraíso y West Elizabeth. Sin embargo, a diferencia de sus precedentes lúdicos y cinematográficos, la música de Red Dead Redemption se comporta en una buena parte del

${ }^{16}$ Red Dead Revolver Soundtrack, <https://reddead.fandom. com/wiki/Red_Dead_Revolver_Soundtrack $>$ [consulta: 15/03/2020]. juego de un modo dinámico y se adapta a las principales situaciones a las que el jugador debe enfrentarse por lo que, en este caso, el proceso de alfabetización ludomusical aparece condicionado por las exigencias tecnológicas. Por ejemplo, para facilitar su combinación dentro del videojuego, todas las piezas que componen la banda sonora están escritas en la tonalidad de La menor y acomodadas a una velocidad de 130 pulsaciones por minuto.

A lo largo del juego se intenta que los tópicos sonoros del spaghetti western reaccionen de forma dinámica en situaciones parecidas a las que el jugador experimentaría si fuera el personaje protagonista de una película de género. Si durante el juego disparamos contra otro personaje sin una razón clara, tendremos que huir de forma inmediata perseguidos por un grupo de agentes. Durante la persecución, el motor del videojuego hará que escuchemos un tema musical en el que aparecen tópicos como campanas, arpas de boca y silbidos, acompañados de otros sonidos diegéticos. Cuando los agentes comienzan a acercarse al personaje controlado por el jugador, la intensidad musical aumenta para generar tensión y si, por el contrario, logramos alejarnos de ellos disminuye progresivamente.

Una situación análoga sucede en los duelos en los que John Marston tiene que enfrentarse a algún antagonista. En este caso se escucha un silbido acompañado por una caja que percute un ritmo de bolero en ostinato que, partiendo de una dinámica suave, va aumentando progresivamente la intensidad hasta el momento en que suenan los disparos (véase Vídeo 1). ${ }^{17}$

La experiencia previa de exposición del jugador a otros productos audiovisuales, adquirida a través de su alfabetización ludomusical, le permite reconocer el código sonoro del silbido acompañado de la percusión como un símbolo del vaquero solitario alerta ante las situaciones de riesgo, un topos musical popularizado por el compositor Ennio Morricone en su célebre Trilogía del dólar, serie de tres películas del género spaghetti western dirigidas por Sergio Leone en la década de los sesenta del siglo XX.

Las referencias intertextuales a la música cinematográfica y a los juegos anteriores de la saga fueron también tenidas en cuenta a la hora de diseñar la última entrega de

17 Los ejemplos tomados de videojuegos presentados aquí pueden visionarse en la versión digital de este artículo en el portal web de Anuario Musical. 


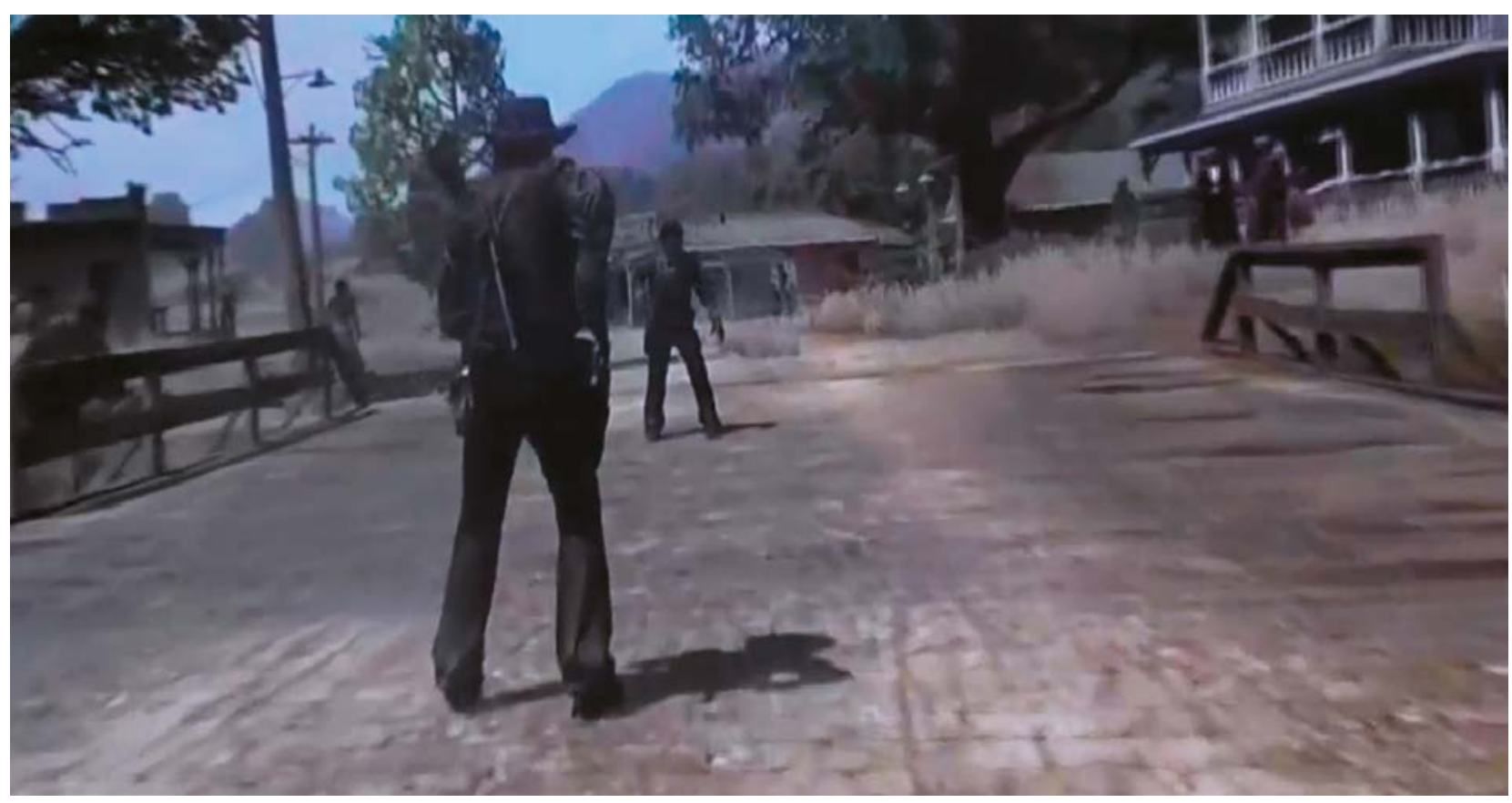

Vídeo 1. Red Dead Redemption (Rockstar, 2009). Escena de un duelo.

la serie de videojuegos, Red Dead Redemption 2, publicada en 2018. En esta ocasión, no obstante, se intentó superar la reproducción literal o simple imitación de códigos sonoros para remarcar que, desde el punto de vista argumental, el nuevo videojuego se consideraba una precuela del anterior. Rockstar Games, la empresa desarrolladora, se planteó crear un nuevo diseño de sonido que, sin perder las esencias del juego, sirviera para contextualizar un juego de forajidos del lejano Oeste que se sitúa en 1899.

Como es bastante frecuente en el mundo de los videojuegos, para comenzar a trabajar en el diseño de sonido de Red Dead Redemption 2 se tomaron como punto de partida una serie de referencias sonoras como el álbum Teatro (1998) del cantante y compositor norteamericano Willie Nelson y la banda sonora de Bruce Langhorne para la película de 1971 Hombre sin fronteras (The Hired Hand) dirigida por Peter Fonda. Esta última se incluyó porque evocaba un paisaje sonoro que, sin perder las raíces con la música folk norteamericana, se alejaba de los estereotipos del cine de género. ${ }^{18}$ Además, se intentó también imitar la sonoridad del grupo Wrecking Crew, un

18 Red Dead Revolver Soundtrack. conjunto versátil de músicos de estudio que trabajaron en Los Ángeles en las décadas de los años 60 y 70 con artistas como Frank Sinatra, Cher o Art Garfunkel entre otros muchos..$^{19}$ A partir de estas referencias, Woody Jackson se planteó componer una banda sonora que obviara los gastados códigos sonoros cinematográficos, pero sin perder de vista que los jugadores debían seguir reconociendo el resultado como parte del ambiente sonoro del lejano Oeste. Para ello, Jackson se centró especialmente en la renovación de los elementos tímbricos. Reemplazó, por ejemplo, las campanas habituales en el spaghetti western por una mandolina e introdujo otros instrumentos, como el violín, el arpa de boca, la jarra (jug) o la armónica, que se tocaban en las jug bands, conjuntos musicales populares en la Norteamérica de principios del siglo XX.$^{20}$ Asimis-

19 Elias Leight, "The 'Red Dead Redemption 2' Soundtrack Might Be the Biggest Album of 2018", Rolling Stone, 18/12/2018. Accesible en <https://www.rollingstone.com/mu$\mathrm{sic} /$ music-features/the-making-of-red-dead-redemption-2-soundtrack-766210/> [consulta: 15/03/2020].

${ }^{20}$ La jarra (jug) era un recipiente de barro o vidrio destinado originalmente a contener bebidas alcohólicas o agua. Se tocaba canturreando a través de ella y se conseguían sonidos con un timbre 
mo, se incluyeron melodías originales adecuadas al contexto histórico en el que se desarrolla el juego, que son interpretadas de un modo realista por NPCs o personajes no jugables (en inglés Non Playable Character) con los que el jugador puede interactuar o limitarse a escuchar su interpretaciones.

Como se ha visto en los ejemplos precedentes, la originalidad o la complejidad no son características significativas de la música de videojuegos, pero existe una razón de peso para ello. El aprendizaje e identificación de los códigos sonoros que comporta la alfabetización ludomusical debe alcanzarse con facilidad. Cuando la música tiene un papel importante para la interacción se hace necesario que el jugador sea capaz de identificar e interpretar, con la mayor precisión posible, los códigos que se va encontrando a lo largo del juego. Reconocer el valor del sonido de una melodía silbada antes de un duelo puede ser crucial para estar preparado a la hora de resolver adecuadamente la situación que plantea la escena. De este modo puede verse que, cuando se apoya en una intertextualidad sonora basada en lugares comunes conocidos por los jugadores, el proceso de alfabetización ludomusical se convierte en uno de los aspectos definitivos para que el jugador consiga la inmersión en el espacio videolúdico. ${ }^{21}$

\subsection{La música de los videojuegos en el contexto de otros juegos: diseño y mecánicas}

La alfabetización lúdica incluye también, según Zagal, la relación contextual que se establece entre el videojuego analizado y otros juegos, sean o no digitales. Con esta categoría se trata de comprender las convenciones y decisiones de diseño que vienen definidas por elementos como las mecánicas que proceden de otro videojuego con el que se comparte una misma filiación o con otros juegos tradicionales analógicos que han servido de inspiración o referencia para el diseño. Un ejemplo de ello serían los puntos de experiencia que un personaje obtiene por realizar acciones concretas como recoger objetos, completar misiones o superar determinados retos, gracias a los cua-

similar al de una tuba o trombón. Puede escucharse un ejemplo en $<$ https://soundcloud.com/world-music-network/whats-that-tasteslike-gravy $>$.

${ }^{21}$ Van Elferen, "Analysing Game Musical Immersion", p. 37. les el jugador consigue mejorar las características o habilidades de su personaje.

En el campo musical, este tipo de relación supone reconocer, a través del proceso de alfabetización ludomusical, aquellos elementos que aparecen integrados en los videojuegos como parte de su mecánica y que poseen un significado informativo específico para el jugador. En la gran mayoría de los videojuegos, los elementos sonoros están presentes en los momentos más decisivos e indican, por ejemplo, si se han ganado determinados puntos con una acción, si los objetos que se han recogidos son los correctos o si el personaje que se controla tiene muchos enemigos al acecho. De este modo, un glissando o slide ascendente o descendente suele simbolizar la ganancia o pérdida de energía del personaje a lo largo del juego y el sonido agudo de una pequeña campana o de un glockenspiel se relaciona comúnmente con la recompensa obtenida por un objeto recolectado.

La asociación de los sonidos o gestos musicales con las acciones o situaciones del juego no supone un hecho arbitrario, ya que responde a un proceso de codificación sonora que se generó a lo largo del siglo XX y que se origina en las primeras máquinas de pinball (o máquina de/l millón) y otros predecesores mecánicos y electromecánicos que incorporaron el sonido como parte de la configuración de sus parámetros estéticos. Aunque es evidente que, en la actualidad, gracias a la tecnología puede comunicarse mucha más información a través del sonido - por ejemplo, con la espacialización, las frecuencias más precisas, los cambios de timbre o los efectos de procesamiento de la señal digital - como sugiere Karen Collins, la función de proporcionar información básica al jugador a través de determinados rasgos sonoros, continúa siendo un elemento importante en los videojuegos actuales. ${ }^{22}$

\subsection{La música de los videojuegos en el contexto de la plataforma de sonido}

Para comprender adecuadamente la naturaleza y los valores del videojuego es preciso tener en cuenta también los medios tecnológicos en donde se reproduce y las restricciones o posibilidades técnicas de cada uno de los dispositi-

${ }^{22}$ Karen Collins, "Game Sound in the Mechanical Arcades: An Audio Archaeology", Game Studies, 16/1 (2016) < http://gamestudies.org/1601/articles/collins $>$ [consulta: 15/03/2020]. 
vos en los que se implementa. Este aspecto es especialmente significativo en el ámbito de la música y el sonido, en donde el investigador debe ser consciente de los avances que se han producido en las últimas décadas para tener referencias precisas del ambiente acústico de cada género y ubicar, tanto desde el punto de vista sincrónico como diacrónico, los posibles códigos sonoros que puede encontrarse en un videojuego. Por ejemplo, si se desea profundizar en la estética musical de series de videojuegos ya clásicos como The Legend of Zelda o Super Mario Bros — aún vigentes a través de las últimas versiones de los juegos y de su permanencia en el repertorio de versiones sinfónicas o de arreglos difundidos a través de Youtube- se hace imprescindible conocer las características técnicas de la Nintendo Entertainment System (NES), una de las videoconsolas con mayor éxito de ventas en los años 80 y 90 del siglo XX para la que se crearon los primeros juegos de estas series.

Lanzada a partir de 1985, la NES disponía de un chip de sonido (Ricoh RP2A03) con cinco canales. Dos de ellos eran ondas cuadradas que permitían varias opciones para configurar el timbre. Una de estas ondas podía variar la frecuencia para crear efectos de glissando o slides, adecuados para los sonidos de disparos de pistolas láser o platillos volantes. El tercer canal era una onda triangular, una octava más grave que los de las ondas de pulso y estaba bastante limitado en cuanto a la afinación. El cuarto canal producía ruido blanco y se empleaba habitualmente para emular instrumentos de percusión y otros efectos. El último canal permitía recoger muestras o samples de referencias reales con modulación delta (analógico-digital), poniendo a disposición del compositor una rudimentaria versión de sonidos de 1-bit. ${ }^{23}$

Las limitaciones tecnológicas del chip de la NES contribuyeron a desarrollar nuevas estrategias compositivas que se incorporaron a la estética sonora de los productos de la marca Nintendo. Por ejemplo, para generar una mayor riqueza armónica, dado que solo podían escucharse simultáneamente tres de los cinco canales, fue habitual emplear arpegios a una gran velocidad en uno de los canales, con el fin de crear una sensación de polifonía en un único canal monofónico. De este modo, se liberaban los

\footnotetext{
${ }^{23}$ Sobre las características técnicas del chip de sonido Ricoh RP2A03, véase FamiTracker wiki <http://famitracker.com/ wiki/index.php?title=Main_Page $>$ y Brad Taylor, 2A03. Technical reference $<$ http://nesdev.com/2A03\%20technical\%20reference.txt $>$ [consulta: 15/03/2020].
}

dos canales restantes para colocar una o dos melodías que podían trabajarse de forma contrapuntística o enriquecerse con redoblamientos y distintos efectos tímbricos. En el breve loop titulado Poison Mind que Kinuyo Yamashita compuso para la lucha contra uno de los enemigos en Castlevania (Konami, 1987), se evidencia el empleo de esta técnica de instrumentación. Con una textura a dos voces reforzada, en uno de los dos canales de onda cuadrada se sitúa un rápido arpegio en semicorcheas. La onda triangular, que no permite el control de intensidad, se emplea para un bajo armónico que evoluciona sobre los grados tonales, mientras que el canal generador de ruido simula efectos de percusión; véase Video 2.

El proceso de alfabetización ludomusical, que se verificaría a través de la identificación del resultado sonoro con los conocimientos teóricos previos sobre el desarrollo técnico de las videoconsolas, facilitaría al investigador que escuche el anterior loop de Castlevania, la identificación de sus rasgos estéticos y ayudaría a ubicarlo en el marco cronológico de las videoconsolas de tercera generación que se fabricaron en los años 80 del siglo XX.

\subsection{Deconstruir el videojuego para entender la música}

Comprender el funcionamiento de los diferentes componentes que forman parte de la estructura de un videojuego, cómo interaccionan y facilitan determinadas experiencias a los jugadores, es el último de los aspectos que, siguiendo el modelo planteado por Zagal, puede contribuir al proceso de alfabetización ludomusical.

La forma cíclica de las actividades y misiones que tienen que superarse en los juegos de rol japonés o JPRGs (siglas en inglés de Japanese Role Playing Games) ayuda a entender que, en el ámbito videolúdico, escuchar una misma música con pocas variaciones puede ser, paradójicamente, un medio efectivo para generar significado. La estructura musical que modela la experiencia de juego en un JPRG suele contar con ocho loops o piezas breves relacionadas con situaciones o lugares del juego. Se trata de un mismo esquema reiterativo que replica las líneas generales del modelo establecido por el compositor Koichi Sugiyama en la partitura realizada para el primer juego de la serie $\mathrm{Dra}$ gon Quest (Enix, 1986). ${ }^{24}$ De las ocho piezas musicales que

${ }^{24}$ Patrick Gann, “The 'Eight Melodies' Template: How Sugiyama Shaped RPG Soundtracks", RPGFan <https://web.archive.org/ 


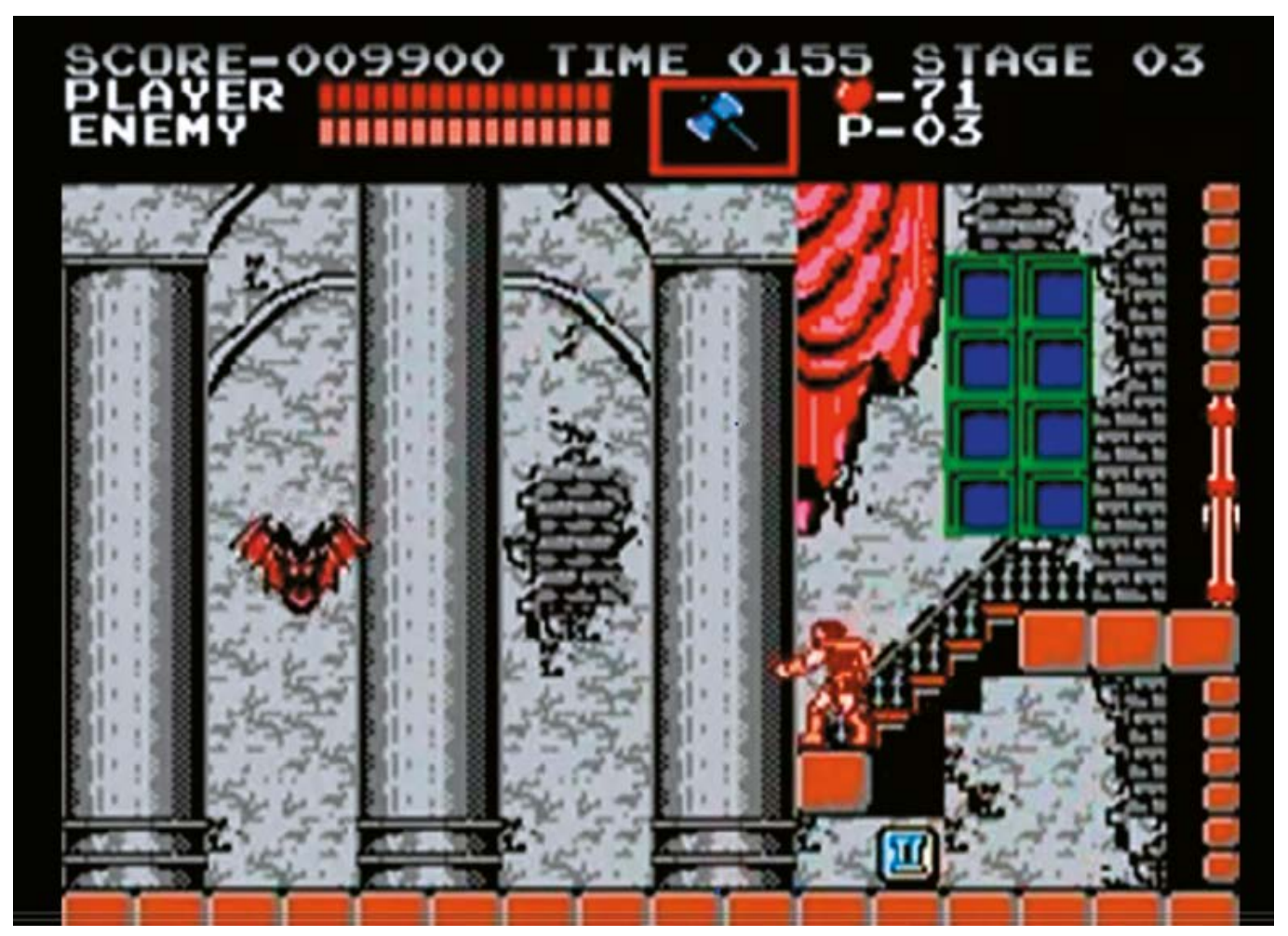

Vídeo 2. Breve loop titulado Poison Mind de Kinuyo Yamashita para el videojuego Castlevania (Konami, 1987).

suelen aparecer en este género de juegos, cuatro de ellas representan una localización sonora estandarizada de los ambientes o lugares por los que el jugador tiene que pasar: castillo, ciudad, campo y mazmorra. Las cuatro restantes se emplean para diferentes puntos unidos a la propia estructura lúdica. La primera pieza musical en forma de loop es la introducción o presentación del juego y en ocasiones también incluye una cinemática breve en donde se contextualizan los rasgos de personajes o narrativa. La segunda suele representar sonoramente una situación de combate y la tercera pieza ilustra la lucha final contra un antagonista. La última música que se escucha en el juego se relaciona con la victoria final y la música de los créditos de salida. ${ }^{25}$

web/20111016020559/http://rpgfan.com/editorials/2008/11-29. html $>$. Archivado del original publicado el 29/11/2009 [consulta: 15/03/2020].

${ }^{25}$ William Gibbons, "Music, Genre and Nationality in the Postmillennial Fantasy Role-Playing Game", en The Routledge Companion to Screen Music and Sound, ed. Miguel Mera, Ronald Sadoff y Ben Winters (Nueva York: Routledge, 2017), p. 418.
El empleo del mismo esquema de ocho piezas, codificado a lo largo de más de tres décadas, se ha convertido en un elemento firmemente unido a la identidad de los JRPGs. Gracias al aprendizaje que comporta la exposición a otros títulos del mismo género, un jugador es capaz de identificar y dotar de significado, desde un primer momento e incluso sin conocer el juego previamente, cada uno de los loops que escucha mientras se desplaza por las distintas zonas del juego.

El proceso de alfabetización ludomusical que supone la codificación de las ocho piezas musicales que incorporan los juegos de rol japoneses ha traspasado también el mundo videolúdico y se ha incorporado al ámbito pedagógico. Se produce así una curiosa circunstancia donde un modelo musical funciona con un carácter didáctico tanto en el mundo virtual como en el real. Tim Summers ha estudiado la utilización de un esquema de ocho piezas breves contrastantes, tomadas de videojuegos de rol japoneses, en un volumen de materiales didácticos publicados como parte del currículo oficial utilizado para la enseñanza de música en las es- 
cuelas elementales de Japón. ${ }^{26}$ Dado que se trata de un libro cuyos contenidos han sido sometidos a un escrutinio de las autoridades, la presencia en el ámbito pedagógico del citado esquema parece revelar también una práctica consciente de alfabetización ludomusical promovida desde las instituciones oficiales para educar a las nuevas generaciones en los códigos y en la estética de la música de videojuegos creada en Japón.

\section{MODELANDO EL ANÁLISIS DE LA MÚSICA DE LOS VIDEOJUEGOS}

Como parte de un medio complejo y multidimensional, la música de los videojuegos requiere una aproximación que comporta la utilización de fuentes, materiales y metodologías distintas a las empleadas en otro tipo de análisis musicales. El audio de un videojuego no es siempre lineal y en muchas ocasiones tiene que adaptarse a las reacciones del jugador. Debido a su inmediatez, interactividad y jugabilidad, la música videolúdica se percibe esencialmente como un evento en tiempo real del cual una partitura tradicional solo podría representar una imagen desenfocada de su contenido. Por esta razón, a la hora de analizar las composiciones musicales realizadas para videojuegos, el investigador no se puede limitar a estudiar su estructura, los contenidos armónicos o contrapuntísticos o la instrumentación. Tiene que abordar también aspectos específicos del medio, como el papel que tiene la música en la inmersión, en la narrativa del juego, en la relación entre la música y el movimiento del jugador - que se trabaja en el diseño cinestésico - o las ventajas y limitaciones de la tecnología disponible, entre otros. Enfrentarse al análisis de la música de un videojuego supone, por tanto, desarrollar nuevos planteamientos metodológicos y trabajar con fuentes que no son habituales en la práctica del trabajo común de un musicólogo.

Para explicar cómo los contenidos sonoros se relacionan con el gameplay, ${ }^{27}$ señalar los puntos donde se producen los cambios dinámicos, transiciones o inte-

26 Timothy Summers, "Mother/EarthBound Zero and the Power of the Naive Aesthetic: No Crying Until the Ending" en Music in the Role-Playing Game: Heroes \& Harmonies, ed. Steven Reale y William Gibbons (Nueva York: Routledge, 2019), pp. 50-51.

27 En este contexto, gameplay se entiende como el conjunto de acciones que un jugador realiza para interactuar con el juego o la forma en la que el juego interactúa con el jugador. rrupciones de la música o aquellos momentos en los que el motor del juego reacciona musicalmente de una manera diferente a las expectativas del jugador, el investigador debe tomar en sus manos el mando de su videoconsola u ordenador y dedicar parte de su tiempo a jugar con una visión analítica y crítica. Jugar de un modo convencional, siguiendo los itinerarios o instrucciones indicadas, puede ser un buen modo de comenzar a conocer las líneas generales de la actividad musical en relación con las mecánicas del juego. En ocasiones, es conveniente realizar una experiencia de juego "reaccionaria", lo que supone actuar en contra de lo previsible - por ejemplo, llevando a un personaje a un lugar diferente del que nos indica el juego o haciéndole caminar despacio cuando se espera que huya de inmediato - con el fin de conocer la reacción de la música en el caso de que se subviertan las expectativas. Asimismo, una experiencia de "juego reincidente" - jugando de nuevo un mismo nivel, pero observando los momentos en los que se mantiene o cambian las condiciones musicales - puede ser interesante para detectar, por ejemplo, posibles problemas provocados por los dispositivos tecnológicos en las transiciones, velocidades de fundido entre dos pistas o en las reiteraciones de las secuencias en looping. Esta metodología basada en el juego analítico resulta muy recomendable, especialmente cuando se pretende analizar un juego que contiene música generativa o procedural, técnica que permite la creación de música en tiempo real controlada por algoritmos; esto sucede, por ejemplo, en el videojuego No Mans' Sky (Hello Games, 2016), una aventura de exploración espacial con un universo abierto que se ambienta con música minimalista compuesta por el grupo británico de rock experimental electrónico 65 daysofstatic (véase Video 3).

En este tipo de juegos puede ser también interesante estudiar el código de programación que afecta a la música o el funcionamiento de los sistemas middleware ${ }^{28}$ con los que se implementan los objetos sonoros -como, por ejemplo, FMOD, Wwise o Microsoft Direct Music-, si bien no siempre es posible conseguir esta información que, por lo general, suele estar protegida por derechos de autor.

${ }^{28}$ Con sistemas middleware nos referimos aquí a una plataforma flexible o librería de código reutilizable que proporciona las funciones básicas para desarrollar la implementación de una aplicación de juego. 


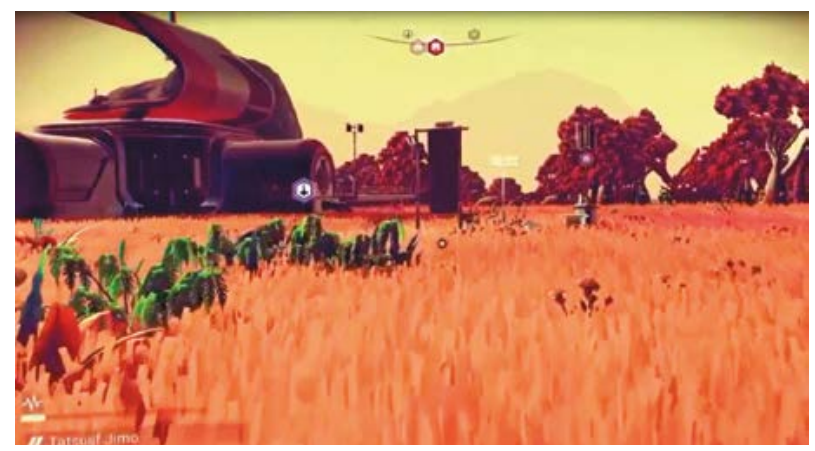

Vídeo 3. Música minimalista del grupo 65daysofstatic como ejemplo de música generativa para una escena del videojuego No Mans'Sky (Hello Games, 2016).

Acceder a los contenidos musicales del juego no suele ser tampoco una tarea fácil. En algunos productos es posible extraer los archivos, por ejemplo, en formato MIDI, lo que puede facilitar la labor de transcripción musical de la que debe ocuparse habitualmente el investigador para suplir la carencia de partituras fiables que reproduzcan de un modo exacto la música que se escucha en el juego. Salvo en algunas ocasiones en las que los compositores ponen a disposición del público las partituras de algún tema musical - como ocurre por ejemplo con las piezas para piano solo compartidas por Garry Schyman de la música que compuso para la saga BioShock-, ${ }^{29}$ los materiales que figuran en la red suelen ser transcripciones realizadas por aficionados que no siempre reflejan con fidelidad los contenidos sonoros del juego. Las antologías con arreglos publicadas por editoriales comerciales pueden ser también instrumentos útiles para el análisis, sobre todo si en ellas ha participado el compositor. ${ }^{30}$

Para suplir o complementar los datos obtenidos en la indagación realizada a través de los elementos que contiene el propio juego, suele ser también interesante emplear otras fuentes secundarias, tal y como señala Tim Summers. ${ }^{31}$ Si bien no resulta fácil acceder a este tipo de

${ }^{29}$ Véase el siguiente enlace: <http://garryschyman.com/ sheet-music/> [consulta: 15/03/2020].

30 Puede citarse como ejemplo la antología de la banda sonora compuesta por Austin Wintory para el videojuego Journey en versión arreglada para piano. Austin Wintory, Journey: Sheet Music Selections from the Original Video Game Soundtrack (Van Nuys, CA: Alfred Music, 2013).

${ }^{31}$ Tim Summers, Understanding Video Game Music (Cambridge: Cambridge University Press, 2016), pp. 44-50. información, las empresas desarrolladoras a veces divulgan los informes y documentos de producción o Game Design Documents (GDD) que en ocasiones incluyen descripciones detalladas sobre cómo se plantea relacionar la música con las mecánicas y la narrativa del juego. En cambio, las grabaciones de la banda sonora comercializadas a través de soportes como el CD o divulgadas en formato digital, deben emplearse con precaución. Por lo general se trata de versiones parciales remezcladas y arregladas de nuevo que ofrecen una fotografía estática de los contenidos musicales, descontextualizados de la propia narrativa, que carecen de la parte dinámica y de las aportaciones derivadas de las acciones del jugador. Asimismo, para profundizar en la relación que establecen los jugadores con la música de un videojuego concreto puede ser también interesante, como sugiere Summers, analizar las críticas publicadas en comunidades especializadas en la red y los comentarios en foros y videos de Youtube, una sugestiva propuesta metodológica que enlaza con los estudios de recepción. ${ }^{32}$

\subsection{Inmersión y performatividad}

Analizar la música de los videojuegos no solo es una manera de ampliar los temas de investigación de la musicología, sino que, además, puede conducir a ampliar las perspectivas analíticas en la propia disciplina. A diferencia de lo que sucede en otras situaciones en las que se produce el fenómeno de la escucha musical, en los videojuegos, el usuario-jugador es parte indispensable de un proceso productivo en donde se generan efectos cognitivos particulares como la inmersión, un estado de conciencia que es resultado directo de los procesos de interacción que precisa el medio.

Isabella van Elferen, profesora de la Kingston University (Londres), ha desarrollado un modelo integral para estudiar la relación que se establece entre los elementos musicales de los videojuegos y la inmersión. ${ }^{33}$ El denominado modelo ALI (Affect, Literacy, Interaction) propone tres conceptos de trabajo superpuestos, el afecto musical, la alfabetización mediática y la interacción, que cooperan en el proceso de significación e identificación de la música de los videojuegos. Como componente psicológico, el afecto está relacionado con la memoria, la emoción y la

32 Summers, Understanding Video Game Music, pp. 49-50.

33 Van Elferen, “Analysing Game Musical Immersion”. 
identificación. Con este modelo se llama la atención sobre las importantes conexiones emocionales que los jugadores de videojuegos crean a través de la música. Se trata de una inmersión afectiva que genera significados subjetivos e impredecibles, pero que puede ser guiada a través del segundo de los elementos que componen el modelo de análisis: la alfabetización mediática entendida esta como los conocimientos previos sobre determinados tropos y convenciones musicales que el jugador ha asimilado de forma más o menos consciente a través de otros medios audiovisuales. Por ejemplo, escuchar el sonido de un violonchelo con motivos disonantes en la zona más grave de su tesitura puede ser interpretado como el preludio de una fatalidad, debido a que con frecuencia el jugador ha escuchado este gesto sonoro en una situación similar de una película de terror.

Para van Elferen la interacción musical en los videojuegos, tercero y último de los conceptos del modelo ALI, se produce tanto con situaciones performativas en las que el gameplay se basa en el control por el jugador de elementos musicales, - por ejemplo, en los juegos de acción rítmica en donde se emula la interpretación de un tema musical-, como en aquellos en los que el jugador puede controlar la música diegética del juego - apagando un receptor de radio que el personaje está escuchando en su coche; la interacción musical también se produce en situaciones en las que la música extradiegética contribuye a guiar al jugador por el espacio. El análisis del modo en que los tres elementos, afecto musical, alfabetización mediática e interacción, confluyen en el diseño del sonido de un videojuego permite conocer de un modo preciso las mecánicas de la inmersión musical y proporciona, además, una interesante conexión entre los datos que pueden obtenerse empíricamente y la reflexión teórica.

El estudio de los citados aspectos performativos de la música de los videojuegos conforma otra de las productivas líneas de investigación que se han comenzado a gestar en los últimos años, en donde la Ludomusicología converge con otras áreas de investigación como la pedagogía musical o la psicología. Entender la música no solo como una vivencia o un conjunto de acciones complejas que producen una experiencia activa y participativa, como sintetiza la expresión "musicar" (musicking) creada por Christopher Small, ${ }^{34}$ permite ampliar el concepto de

${ }^{34}$ Christopher Small, Musicking: The Meanings of Performing and Listening (Middletown, CT: Wesleyan University Press, 1998). interpretación musical para poder incorporar nuevas formas de producir música mediadas por interfaces lúdicas.

Los llamados videojuegos musicales, en los que el centro del gameplay es la propia música, brindan oportunidades de diversión y aprendizaje específicas y pueden llegar a ser un valioso complemento para un programa de educación musical. Esta tipología de juegos comporta una participación activa en una nueva forma de interpretación musical que, como ha sido demostrado en estudios empíricos, contribuye a mejorar la memoria, la creatividad, el ritmo o la afinación en un amplio espectro de la sociedad que no puede invertir el tiempo y/o el dinero requerido para aprender un instrumento musical. ${ }^{35}$ Por ejemplo, en un videojuego ya clásico como Rock Band (Harmonix, 2007), los jugadores pueden elegir entre interpretar diferentes temas musicales con la batería, el bajo, la guitarra o la voz, ya sea como solista o como conjunto. En este juego los bateristas tocan una batería patentada que consta de cuatro pads electrónicos, platillos y un pedal de bombo. Los guitarristas y bajistas usan controladores que se parecen a sus respectivos instrumentos, pero las cuerdas y la púa son sustituidos por cinco botones de colores en el mástil y un interruptor de palanca de efectos. Un micrófono permite que el juego analice la afinación y el ritmo de los vocalistas. Todos los jugadores disponen de una "partitura" no convencional o representación gráfica de la música que deben interpretar en forma de scroll (rollo) vertical. Estos gráficos se sincronizan con una grabación en audio. La puntuación que se obtiene se basa en la precisión rítmica de los jugadores-percusionistas y también melódica en el caso de los jugadores-guitarristas; en los vocalistas se evalúa, además, la afinación.

Las posibilidades de expresión y control a través de las interfaces de los videojuegos musicales, como el citado Rock Band y otros juegos similares como Guitar Hero (Harmonix, 2005) o Rocksmith (Ubisoft, 2011), han llevado a considerar la necesidad de redefinir la noción de instrumento musical. Las similitudes entre los controladores de videojuegos y los instrumentos acústicos o eléc-

35 Véanse a este respecto Kylie Peppler, Michael Downton, Eric Lindsay y Kenneth Hay, "The Nirvana Effect: Tapping Video Games to Mediate Music Learning and Interest", International Journal of Learning and Media, 3 (2011), pp. 41-59; y Amanda C. Pasinski, Erin E. Hannon y John S. Snyder, "How Musical are Music Video Game Players?", Psychonomic Bulletin \& Review, 23 (2016), pp. 1553-1558. 
tricos invitan a extender la definición convencional de instrumento musical para poder incluir cualquier dispositivo capaz de producir sonidos que sea controlado por una serie de gestos físicos y que reaccione a los inputs del usuario, como sucede en muchos videojuegos musicales en los que, a través de interfaces electrónicas tengan o no forma de instrumento musical - los jugadores interactúan físicamente sobre la interfaz para generar un sonido. ${ }^{36}$ De esta forma, la interpretación musical se amplía al fenómeno complejo de la "síncresis cinesónica" (kinesonic synchresis), exclusiva de los productos interactivos, en donde a través de la sincronización entre acción, sonido e imagen, pueden generarse experiencias multisensoriales. ${ }^{37}$

\subsection{Realidad y virtualidad. Nuevas formas de diégesis musical}

La búsqueda de herramientas conceptuales adecuadas para analizar las relaciones entre los elementos visuales y sonoros de los productos videolúdicos es otro de los ámbitos de trabajo de la Ludomusicología desde sus orígenes.

Las analogías que existen entre los elementos que conforman la estructura de los productos videolúdicos con otros géneros y el hecho de que una importante parte de los videojuegos actuales incorporen bandas sonoras con características similares a las de las grandes producciones de Hollywood, ha propiciado la adopción del binomio diegético/extradiegético. En la teoría literaria y audiovisual es habitual su uso para clasificar la diferencia entre los eventos sonoros que se originan dentro del mundo ludoficcional - como pueden ser los sonidos que proceden de un reproductor de música o de un personaje que, en un momento determinado del juego toque un instru-

36 Sobre la necesidad de redefinir el concepto de instrumento musical, véase Norbert Schnell y Marc Battier, "Introducing composed instruments, technical and musicological implications", en NIME '02: Proceedings of the 2002 conference on new interfaces for musical expression (2002), pp 1-5.

37 Karen Collins, Playing with Sound: A Theory of Interacting with Sound and Music in Video Games (Cambridge, MA: MIT Press, 2013), p. 27. Karen Collins une en este concepto los términos ingleses "kinesonic", acrónimo de kinesthetic (cinestésico) y sonic (sónico), con el de "síncresis", creado por Michel Chion, para definir la unión que se produce entre un fenómeno sonoro y un fenómeno visual. mento musical $-\mathrm{y}$ aquellos otros que, por el contrario, carecen de conexiones directas con una fuente sonora visible o, al menos, sugerida dentro del espacio lúdico. Sin embargo, a diferencia de lo que acontece con otros productos audiovisuales, las fronteras entre los elementos sonoros diegéticos y extradiegéticos en los videojuegos no están siempre definidas con claridad y, en ocasiones, se rompen conscientemente con una finalidad funcional. Mientras que en una proyección cinematográfica los componentes sonoros son inmutables y, consecuentemente, se escuchan siempre del mismo modo cada vez que se repite el visionado, el factor interactivo de los videojuegos hace que todos los sonidos, incluidos los musicales, puedan variar dependiendo directamente de las decisiones y acciones adoptadas por el jugador que se convierte así en un cocreador, involuntario en la mayoría de las ocasiones, del paisaje sonoro del juego. La complejidad de esta propuesta se incrementa en el caso de los juegos multijugador, donde las fuentes sonoras se diversifican de forma proporcional al número de jugadores que participan en la sesión de juego. Se genera así una creación sonora múltiple en tiempo real. En muchos videojuegos pueden adoptarse, además, decisiones para adecuar la experiencia acústica a los gustos personales del jugador, como anular la música, regular el volumen de los efectos sonoros u otorgar mayor presencia a los diálogos, e incluso en algunos títulos el jugador puede llegar a personalizar la música del videojuego, adecuándola a sus gustos personales. Por ejemplo, en Grand Theft Auto (Rockstar North, 2013), como sucede también en los juegos anteriores de la misma serie, los automóviles cuentan con varias emisoras de radio que emiten programas centrados en diferentes géneros musicales. El jugador puede seleccionar la emisora que le apetece escuchar o personalizar la escucha con una lista de reproducción en la que se incluyan sus temas musicales preferidos e intervenir directamente, por tanto, en la diégesis sonora.

Como puede deducirse de los ejemplos precedentes, los conceptos teóricos que hasta ahora han sido empleados para el análisis de otros productos audiovisuales no son suficientes para explicar la complejidad de las relaciones que se establecen en los videojuegos entre los elementos sonoros y visuales, lo que ha generado la necesidad de plantear nuevos desarrollos teóricos para modificar el marco conceptual de referencia. Kristine Jørgensen propone el concepto "transdiegético" (transdiegetic) para definir aquellos sonidos, incluidos los de carácter musical, que no proceden de una fuente del juego, pero que 
mantienen la capacidad para informar sobre eventos que suceden dentro de él. ${ }^{38}$ La idea de Jørgensen enfatiza la importancia funcional de la música y los sonidos en relación con las acciones del jugador y llama la atención sobre las nuevas relaciones que se establecen entre sonido y espacio en el mundo ludoficcional.

La "transdiégesis" plantea dos subcategorías. En la primera, denominada sonidos transdiegéticos externos (external transdiegetic sounds), se incluyen aquellos eventos sonoros que no mantienen una referencia directa con una fuente sonora del juego pero que servirían para comunicar información sobre aspectos diegéticos, por ejemplo, al generar al jugador feedback sobre sus propias acciones. Dentro de los sonidos transdiegéticos externos se podría englobar también la música de ambiente adaptativa, una banda sonora que acompaña al jugador de forma dinámica, que genera un input proveniente del juego y permite que las decisiones de los jugadores puedan influir en determinados parámetros musicales y en cómo las piezas evolucionan en el tiempo. La ubicación en el espacio del personaje que se controla, la presencia de enemigos o el estado de salud son factores decisivos para adaptar los contenidos musicales a la experiencia de juego y a las emociones que se generan. La segunda subcategoría de la propuesta de Jørgensen son los sonidos transdiegéticos internos (internal transdiegetic sounds), aquellos que parten de fuentes diegéticas pero que, en principio, parecen no tener relación con el mundo del juego. Su función principal es, sin embargo, comunicarse de forma directa con el jugador ubicado en el mundo real y crear una sensación de abstracción de un sonido diegético. Muestra de ello podría ser la alusión de uno de los personajes, a través de una ráfaga musical o con un diálogo directo, a las acciones realizadas por el jugador.

El concepto de "transdiégesis" creado por Jørgensen resulta, además, especialmente útil a la hora de analizar las nuevas relaciones con el sonido que se originan en los productos de realidad virtual, en donde, a través de

38 Kristine Jørgensen, "On Transdiegetic Sounds in Computer Games", Northern Lights: Film and Media Studies Yearbook, 5 (2007), pp. 105-117, y, de la misma autora: A Comprehensive Study of Sound in Computer Games: How Audio Affects Player Action (Nueva York: Edwin Mellen Press, 2009) y “Time for New Terminology? Diegetic and Non-diegetic Sounds in Computer Games Revisited", en Game Sound Technology and Player Interaction: Concepts and Developments, ed. Mark Grimshaw (Hershey, PA: IGI Global, 2001), pp. 78-97. sensores biométricos o micrófonos pueden llegar a vincularse con el juego - y traducirse en una información de carácter rítmico - sonidos externos, como los latidos del corazón o la respiración del jugador. Esta información puede incorporarse, por ejemplo, a una banda sonora generativa con el fin de adaptar los eventos musicales a los parámetros biológicos del jugador que potencia su inmersión en el juego al intervenir en tiempo real en la cocreación de la música y en la propia diégesis sonora.

En algunas situaciones la música de los videojuegos puede llegar a crear también su propia virtualidad, su propio flujo (flow) y mantener así la independencia con otros componentes del juego con los que se relaciona de un modo interactivo para complementar o intensificar determinados aspectos. A diferencia de lo que sucede en otros productos audiovisuales, en los videojuegos la música puede extender un espacio virtual autónomo en aquellos puntos en los que se desee incrementar las cualidades inmersivas y diegéticas. Por ejemplo, si en una secuencia cinematográfica de suspense o terror se prescindiera de la música y del sonido de forma persistente, obviando incluso el efecto del silencio para los momentos de máxima tensión, aunque se perdería parte de la efectividad que nos comunican los códigos sonoros, los elementos esenciales del mensaje se continuarían transmitiendo al espectador. Pero si, en cambio, se aplicara el mismo procedimiento en determinados videojuegos del género de terror y supervivencia (survival horror), la carencia de feedback o retroalimentación sonora haría difícil que el jugador tuviera las referencias suficientes para avanzar en el juego.

Consciente de las limitaciones terminológicas para definir situaciones como la que acabamos de describir, Isabella van Elferen propone una ampliación de las categorías diegético y extradiegético e introduce el concepto de sonidos "semidiegéticos" (half-diegetic) para definir aquellos escenarios en donde los sonidos diegéticos se fusionan con la música no diegética y los sonidos de la interfaz. ${ }^{39}$ La complejidad de los contextos en los que se producen estas situaciones en algunos videojuegos, en donde se solapan realidad y virtualidad, puede apreciarse con una experiencia de juego analítico en uno de los ejemplos del videojuego Resident Evil 4 (Capcom, 2005) a los que alude van Elferen. En este juego de terror, el

39 Isabella van Elferen, "Un Forastero! Issues of Virtuality and Diegesis in Videogame Music", Music and the Moving Image, 4/ 2 (2011), pp. 30-39. 
protagonista Leon S. Kennedy tiene que rescatar a la hija del presidente de los Estados Unidos que ha sido secuestrada por una organización ubicada en España de la que forman parte una horda de violentos zombis con aspecto de aldeanos. La secuencia analizada ilustra el momento en el que el protagonista irrumpe en el espacio habitado por estos zombis furiosos. Cuando Leon entra en su campo de visión, comienza a escucharse en primer plano el ruido de una motosierra que encadena con el grito diegético, perfectamente identificable, de uno de los zombis que avisa al resto de sus compañeros de la presencia del personaje: “¡Un Forastero!”. Para potenciar el efecto de inmersión, la voz gritada se acompaña con una breve ráfaga musical estática de carácter disonante y extradiegético (véase Vídeo 4).

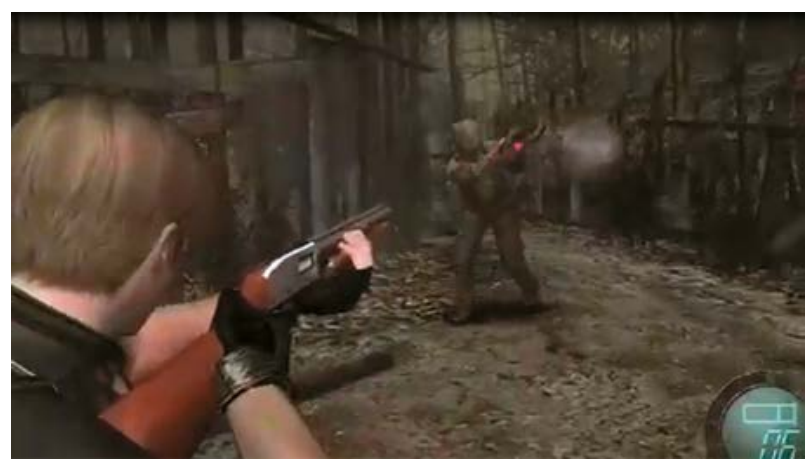

Vídeo 4. Grito “¡Un Forastero!” a cargo de un zombie en Resident Evil 4 (Capcom, 2005).

Aunque los personajes no pueden escuchar la música externa a la acción, la amalgama sonora contribuye a modelar para el jugador una situación ambivalente de semidiégesis en donde la música pertenece tanto a la realidad del ambiente sonoro del juego - en forma de signo para subrayar el grito del zombi - como a la virtualidad que supone el hecho de que solo el jugador, y no el personaje que controla, sea el único capaz de escuchar todos los elementos sonoros mezclados.

\section{A MODO DE CONCLUSIÓN. VIDEOJUEGOS Y MUSICOLOGÍA}

Analizar la música de los videojuegos desde una perspectiva académica no solo supone un fin en sí mismo. Los diferentes aspectos estudiados en este artículo han tratado de poner en evidencia algunas aportaciones de la
Ludomusicología para reestructurar categorías, conceptos, métodos y técnicas de análisis necesarias a la hora de aproximarse a la comprensión del papel de la música en nuevas formas de expresión artística derivadas de la cultura digital. Entender, por ejemplo, cómo la música de un videojuego llega a niveles complejos de significación a través del proceso de alfabetización ludomusical o incorporar conceptos como la inmersión o la performatividad a las herramientas habituales de la investigación puede contribuir de un modo eficaz a una renovación drástica de la musicología. ${ }^{40}$

Puesto que los fenómenos audibles que se producen en los videojuegos crean y modelan un espacio sonoro en el que se incluyen las perspectivas y expectativas individuales del jugador, la Ludomusicología plantea también la posibilidad de renovar la comprensión de la música desde el punto de vista de la escucha y la fenomenología, al permitir evaluar críticamente las suturas y fisuras que pueden generarse entre realidad y virtualidad en situaciones sonoras ambivalentes que se generan en entornos lúdicomusicales. Así ocurre en los juegos de acción rítmica citados en este trabajo que combinan funciones diegéticas y no diegéticas del sonido, donde el jugador no solo se centra en la interpretación musical, sino que debe, además, emplear su memoria para responder adecuadamente a los estímulos visuales y sonoros. Se produce así una intensificación de la inmediatez que caracteriza a la interpretación musical convencional. Este tipo de acercamiento puede ser también útil a la hora de estudiar la presencia de la música en los nuevos productos desarrollados para dispositivos de realidad aumentada y realidad virtual, donde se genera una experiencia inmersiva tridimensional y multisensorial, o en juegos basados en algoritmos musicales en los que el jugador no asume un objetivo específico y su experiencia de juego se plasma en experimentar con el sonido, la música e imágenes abstractas.

En un momento líquido en el que las dinámicas generacionales de consumo musical parecen apuntar a una cierta disyunción con los intereses de la Musicología más

40 Véase Isabella van Elferen, "Ludomusicology and the New Drastic", Journal of Sound and Music in Games, 1 (2020), pp. 103-112. Aunque este artículo ha sido publicado a principios de 2020, algunas de las ideas plasmadas en él se conocen desde hace varios años, ya que proceden de una conferencia de 2014 cuyo texto había sido divulgado por la propia autora en diversos repositorios. 
tradicional, el análisis de la contingencia y la interactividad que caracterizan a los productos videolúdicos induce también a reflexionar sobre la actualidad de los objetivos que guían la enseñanza e investigación en el campo de las Humanidades en general y de la Musicología en particular. Estudiar nuevas formas de producir y consumir música, como propone la Ludomusicología, invita a profundizar asimismo en enfoques de investigación como la experiencia musical, el significado y la performatividad, que permiten enriquecer el campo de comprensión de la música en el contexto de la sociedad digital.

\section{BIBLIOGRAFÍA CITADA}

Aracil, Alfredo. "Música y efectos sonoros en los videojuegos. Apuntes sobre la pérdida de su identidad". En La música en los medios audiovisuales, editado por Matilde Olarte Salamanca: Universidad de Salamanca, 2005, pp. 267-282.

Belinkie, Matthew. "Video Game Music: Not Just Kid Stuff". Videogame Music Archive <https://web.archive.org/web/20020613143431/http://www.vgmusic.com/vgpaper.shtml>.

Collins, Karen. "Game Sound in the Mechanical Arcades: An Audio Archaeology". Game Studies, 16/1 (2016), http://gamestudies.org/1601/articles/collins.

__ . "Game Sound: Reverberations". Journal of Sound and Music in Games, 1/1 (2020), pp. 100-102.

- Playing with Sound: A Theory of Interacting with Sound and Music in Video Games. Cambridge, MA: MIT Press, 2013.

FamiTracker wiki <http://famitracker.com/wiki/index. php?title=Main_Page>.

Fernández-Cortés, Juan Pablo. "Por las sendas de la Ludomusicología: tecnología y estética en la música de videojuegos durante el siglo XX". Anales de la Real Academia Canaria de Bellas Artes de San Miguel Arcángel. RACBA, 10 (2017), pp. 195-210.

Gann, Patrick. “The 'Eight Melodies' Template: How Sugiyama Shaped RPG Soundtracks". RPGFan <http://rpgfan.com/editorials/2008/11-29.html.>.

Gibbons, William. "Music, Genre and Nationality in the Postmillennial Fantasy Role-Playing Game". En The Routledge Companion to Screen Music and Sound, editado por Miguel Mera, Ronald Sadoff y Ben Winters. New York: Routledge, 2017, pp. 412-427.

González Portillo, Antonio Jesús. "La música en el videojuego como banda sonora: definición, antecedentes históricos y desarrollo hasta la actualidad". Tesis doctoral, Universidad de Málaga, 2010.

Jørgensen, Kristine. “Time for New Terminology? Diegetic and Non-diegetic Sounds in Computer Games Revisited". En Game Sound Technology and Player Interaction: Concepts and Developments, editado por Mark Grimshaw. Hershey, PA: IGI Global, 2001, pp. 78-97. _. "On Transdiegetic Sounds in Computer Games". Northern Lights: Film and Media Studies Yearbook, 5 (2007), pp. 105-117.

- A Comprehensive Study of Sound in Computer Games: How Audio Affects Player Action. Nueva York: Edwin Mellen Press, 2009.

Karbani, Tasneem. Summer research project was music to student's ears, <https://sites.ualberta.ca/ publicas/ folio/45/01/04.html>

Leight, Elias. "The 'Red Dead Redemption 2' Soundtrack Might Be the Biggest Album of 2018". Rolling Stone, 18/12/2018. <https://www.rollingstone.com/ music/music-features/the-making-of-red-dead-redemption-2-soundtrack-766210/>

Márquez, Israel V. "La influencia de los videojuegos en la música popular”. En La música en el lenguaje audiovisual. Aproximaciones multidisciplinares a una comunicación mediática, editado por Teresa Fraile y Eduardo Viñuela. Sevilla: Arcibel, 2012, pp. 511-521.

Montero, Julio. "Pautas compositivas en los videojuegos del siglo XXI". En Reflexiones en torno a la música y la imagen desde la musicología española, editado por Matilde Olarte. Salamanca: Plaza Universitaria Ediciones, 2009, pp. 585-598.

Moreira Cury, Mónica. "La música de los videojuegos: modalidades de uso y su relación con el imaginario social. Un estudio sobre la banda sonora del juego 'Final Fantasy VI'”. Tesis de Máster en Musicología, Universidad de Chile, 2004.

Moseley, Roger. "Playing Games with Music (and Vice Versa): Ludomusicological Perspectives on Guitar Hero and Rock Band”. En Taking It to the Bridge: Music as Performance, editado por Nicholas Cook y Richard Pettengill. Ann Arbor: University of Michigan Press, 2013, pp. 279-318.

Parrilla, Gonzalo. "Conceptualización de la terminología ludomusicológica". Itamar, 5 (2019), pp. 57-68.

Pasinski, Amanda C., Erin E. Hannon y John S. Snyder. "How Musical are Music Video Game Players?". Psychonomic Bulletin \& Review, 23 (2016), pp. 1553-1558. 
Peppler, Kylie, Michael Downton, Eric Lindsay y Kenneth Hay. "The Nirvana Effect: Tapping Video Games to Mediate Music Learning and Interest". International Journal of Learning and Media, 3 (2011), pp. 41-59.

Planells de la Maza, Antonio José. “La emergencia de los Game Studies como disciplina propia: investigando el videojuego desde las metodologías de la Comunicación". Historia y Comunicación Social, 18 (2004), pp. 519-528.

Red Dead Revolver Soundtrack. <https://reddead.fandom.com/wiki/Red_Dead_Revolver_Soundtrack>

Sánchez, Mario. "Las funciones de la música en el videojuego: la función ludoinmersiva". En Pantallas pequeñas, ¿músicas menores?, editado por José A. Bornay Llinares, Vicente J. Ruíz Antón y Jenaro Vera Guarinos. Alicante: Letra de Palo, 2015, pp. 287-302.

Schnell, Norbert y Marc Battier. "Introducing Composed Instruments, Technical and Musicological Implications". En NIME '02: Proceedings of the 2002 conference on new interfaces for musical expression (2002), pp 1-5.

Small, Christopher. Musicking: The Meanings of Performing and Listening. Middletown, CT: Wesleyan University Press, 1998.

Summers, Tim. Understanding Video Game Music. Cambridge, Cambridge University Press: 2016.

. "Mother/EarthBound Zero and the Power of the Naive Aesthetic: No Crying Until the Ending". En
Music in the Role-Playing Game: Heroes \& Harmonies, editado por Steven Reale y William Gibbons. New York: Routledge, 2019, pp. 35-53.

Taylor, Brad. 2A03. Technical reference: <http://nesdev. com/2A03\%20technical\%20reference.txt $>$.

The Witcher Adult Coloring Book. Milwaukie: Dark Horse Comics, 2018.

Van Elferen, Isabella. "Analysing Game Musical Immersion: The ALI Model". En Ludomusicology: Approaches to Video Game Music, editado por Michiel Kamp, Tim Summers y Mark Sweeney. Sheffield, Reino Unido: Equinox, 2016, pp. 32-52.

_. "Ludomusicology and the New Drastic". Journal of Sound and Music in Games, 1 (2020), pp. 103-112.

_. "Un Forastero! Issues of Virtuality and Diegesis in Videogame Music". Music and the Moving Image, 4/ 2 (2011), pp. 30-39.

Wintory, Austin. Journey: Sheet Music Selections from the Original Video Game Soundtrack. Van Nuys, CA: Alfred Music, 2013.

Yilmaz, Recep, Nur Erdem y Filiz Resuloğlu. Handbook of Research on Transmedia Storytelling and Narrative Strategies. Hershey, PA: IGI Global, 2018.

Zagal, José P. Ludoliteracy: Defining, Understanding, and Supporting Games Education. Pittsburgh: ETC Press, 2010.

Recibido: 30.04 .2020

Aceptado: 14.08 .2020 
